\title{
Sustainable Eco-Friendly Organic Carbon Fibers is the future of Textile Industry
}

\author{
*S.M. Imtiazuddin \& Shahbaz Ali Malik \\ Popular Fabrics Ltd. Karachi, Pakistan \\ Corresponding Author Email:simtiazuddin@yahoo.com
}

\begin{abstract}
The textile industry is considered the most ecologically detrimental industry in the world. The eco-problems in the textile industry arise during manufacturing processes and are accepted onward right to the finished product. In the production process, like bleaching and then dying, the subsequent fabric makes a toxin that waves into our ecosystem. Controlling pollution is vital during the production process as manufacturing products is free from the toxic effect. The utilization of rayon for clothing has added to the fast depleting forests. Petroleum-based products are harmful to the environment. An integrated pollution control approach is needed to safeguard our environment from these effects. Luckily there is an availability of more substitutes as a textile industry based on agriculture where organic cotton cultivation may be the probable solution of the sustainable, eco-friendly environment.
\end{abstract}

Keywords: - Eco-friendly fibers, Textile Industry, Sustainability

\section{INTRODUCTION}

After globalization worldwide, economic growth rapidly changed in developing countries. The issue of the environment rose simultaneously because most of the production and manufacturing units were shifted to these countries. In developing countries, environmental issues are not considered a priority, but they are a significant threat to the entire world [1]. Sustainability is the word used to save the Planet in the future. Today, with increased population use, products and their wastes have been increased and have caused hazardous impacts on the environment. This has drawn the attention of organizations and policymakers for sustainable development. The most suitable definition of sustainability recommended by the World Commission on Environment and Development is 'meet the needs of the present without compromising the ability of future generations to meet their needs and desires [2].

Sustainability is worked on four main features like the economy, society, culture, and environment. The question for the future is to make and fulfill the demands and desires by keeping in view about all the wastes and extra materials that are disposing of without thinking about the upcoming new generation, future, and environment; or have to save the Planet in the future. To overcome and solve these issues, we need complete and efficient management systems and resources to implement these systems [1].

\subsection{Role of Sustainability in Textile:}

Focusing on sustainable textile materials, sustainability plays a vital role in textile processing and all steps as today's requirement is to produce eco-friendly goods and have the ability to serve the customer and environment and support the economy of the company. Consider, an example of a cotton T-Shirt; and observed that several steps are involved in its processing, from Cotton fiber to finished goods on the shelves. i.e., the first step is the growth of Cotton in which diverse types of harmful pesticides and chemicals and a lot of water are used. Instead of this, organic Cotton can be grown without using chemicals and harmful materials, and also less water is required for it; thus, one can save the use of lots of water and avoid harmful chemicals. It should be monitored initially how many things are required in the dye industry and are against the sustainable environment like energy resources, packaging materials, etc. That is the responsibility of Government and company management as well as the responsibility of individuals who use the product and then discard it. Therefore a proper management system is required for a healthy environment with equal responsibilities of all. Furthermore, sustainability is a concept and model that has realized the entire textile sector that the increase in demand and desires of the customers influences their spending behavior, on which the textile industry mainly depends [3].

The textile industry starts from agriculture and moves towards the way to retail. Textile manufacturing industries impact the environment in different ways i.e., use of water in growing Cotton, energy consumption in all processes, and use of chemicals and materials in the processing. And the industry is always trying to find solutions for problems like pollution, health matters, global warming, and environmental issues. Subsequently, the need is to create awareness among the company management and people. And it does not affect the company's cost to implement these steps, and the money will be back from the efficient supply chain and competitive advantage in the market [4]. 
Efficiency is fundamentally linked with sustainability. Making "more with less" is the heading step towards sustainability. If different companies and brands produce the goods with quality and use less energy and less inputs, these companies will grow and make a profit naturally. It will also be beneficial for the environment [4]. They are fundamentally linked with sustainability. Making "more with less" is the heading step towards sustainability.

Sustainability has become an essential attribute of today's textile and clothing industry. The process of transforming the textile industry into a more sustainable one is susceptible and needs a lot of knowledge, skills, and commitment. The use of Sustainable fibers in textiles is a part of this process and a step towards this milestone. Organic Cotton has demonstrated strength in textile fashion; it is a much better and valuable alternative to dominant and high-impact fibers. Organic cotton fibers have a wide range of applications. But the use of fibers is not every day in textile fashion products. Cotton has captured a significant market share because of its properties, but cotton growing is not favorable for the environment. It requires a lot of water, pesticides, and fertilizers.

On the other hand, if we consider organic cotton, that is resource-efficient in their growth. The quality and yield of fibers are reasonable, and their application in different industries, especially composite with other natural materials, makes them beneficial fibers. The use of natural fibers is the best alternative or substitute for cotton fiber, and the natural properties of these fibers delimit the environment from destructive forces like hazardous chemicals. The use of these extraordinary fibers opens new markets and trends for fashion companies and the consumer. The use of fibers in the textile fashion industry is minimal in different composites. These fibers have the potential to use in fashion products and other industries to make the environment green. By-products produced from these fibers are also beneficial. The environment is a primary driver for organic cotton industrial and governmental sectors. The requirement for this driver is to give it eco-effective products because future survival depends on it.

\subsection{Sustainable Agriculture and Environment:}

The textile industry is agro-based and has an adjacent association to the agriculture industry, from where it gets its raw materials and provided employment to a large number of rural populations, including weaving, availability of cheap labor, designing of cotton weaving, the climate and, the proximity to raw. Many things connected to agriculture industrialization have severe effects on the environment because many pesticides, chemicals, and water are required to grow the crops. Many fertilizers, pesticides, chemicals, and water are being used to achieve crop production in higher yields in recent decades. As a result of this surface run-off of nitrogen, phosphoric emissions of nitrogen compounds and leakages harm the environment. In the past, the use of fertilizers was much less as compared to these days. The working on eco-friendly plantation and varieties of vegetables and fruits are produced by using new technologies and innovative management systems. The condition of agriculture production is worst because of soil quality. Sustainable agriculture means managing the resources efficiently to satisfy the needs and desires of the people in the shadow of eco-friendly products that can help us to keep our environment sustainable [5].

Things kept on changing with time, and textile researchers tried to find the solution for the impacts of the textile industry on the environment. Consequently, more and more textile manufacturers tried to use and look for Biodegradable and sustainable fibers to overcome the impact of harmful textile chemicals and non-eco processes and find some solutions by new and innovative technologies and processes. Biodegradable fiber comes from sustainable sources and is eco-friendly in characteristics [6]. Textile products are made, sold, used (reuse), and discarded all over the world. So different technologies, processes, methods, and procedures are used in the life cycle of a textile product from fiber to garment stage. These all processes work on the way constructed by market key players like businessmen, politicians, and technologists. Globalization brought all-new ways and changed the old procedures, policies, and a paradigm shift occurred. Because after globalization in the area of fibers, raw material, Government made regulations and retail brands, buyers, and multinational companies build new standards and rules for setting the price and quality. The same things fit for dyeing, processing, and biological processes in the finishing [7]. Spinning, Weaving, Dyeing, Finishing, Cutting and Stitching machinery and technology took more than a decade to shift into a new era. Millions of Euros and Dollars were invested in the research and development of these techniques and ideas. In mature technology, innovation is a requirement for making the system. Its processes are reliable and efficient, and this can be achieved along with performance in the economy and ecology[7]. Data and information about sustainability are provided by scientists in a specific area, environmental sciences, biology, Social Science, toxicology, and many more. Most people don't know about the product and its background in their daily lives. Young generations that are more trendy don't know what they are wearing and where it is coming from, or whether it consists of any harmful material. So the need is to make awareness among the new generation and try to guide the old one about the 
Pakistan Journal of Chemistry 2021

sustainability and how we can keep a check on our daily life product about their origin and materials in it. Sustainability helps the firms and companies become more stable economically and environmentally friendly [7].

\subsection{Recommendations:}

1. Textile companies are using organic cotton in their products in composite form; it is recommended that textile companies enhance the use of organic Cotton in their products to add value to the green product line. Like Bergman AB is using 100 $\%$ organic cotton in their products

2. Bergman products are basic and classic in design; they also make fashionable garments to attract young customers.

3. Textile fashion companies and brands are using organic Cotton in their primary product line and not using it in fashion articles. It is recommended that these brands use organic cotton in their fashion products also.

4. China has organic cotton production of up to $30 \%$. It is recommended that companies and researchers find some other places to grow it in other parts of the world to increase the natural, sustainable production plant that will be helpful to fulfill the future demand for organic Cotton.

5. It is recommended that fashion companies use organic Cotton in their product line to make their products more ecofriendly and comfortable.

6. Organic Cotton is the future fiber of the world; therefore, it is recommended that more search and investigation be required regarding its processing to make its use convenient for fashion companies.

\section{Conclusion:}

The future of the textile industry will depend on the products that have reduced environmental and social burdens during their entire product life cycle. A part of this is introducing sustainable materials that will reduce these impacts during their growth and processing. And this report will provide fashion companies good knowledge of sustainable fibers (the raw material for their products) and a brief description of their properties to support the use of these fibers in their product that will serve society and the environment.

\section{Acknowledgment:}

The author is very thankful to the Management of Popular Fabrics Ltd. Karachi, Pakistan, for providing support during my research work.

\section{References:}

1. Prakash, Nelliyat, "International growth and environmental degradation," PhD Thesis, Tiruppur, India.

2. World Commission on Environment and Development. "Towards Sustainable Development," UN Documents.

3. What does Sustainability of Textile means? http;//wiki.answers.com (accessed April 10, 2010)

4. Scrimshaw, John."'Lean and Green," IMPACT. 2009:2.

5. Ebbersten, Bengt Bodin and Sten. A Sustainable Baltic Region. Uppsala: Baltic University Programmed, 1997.

6. R.S. Blackburn. Biodegradable and Sustainable Fiber, 2005.

7. Tobler-Rohr, Marion Irene. "Sustainable Textile Production for the value Added Chain. http://www.emsc.ch/Feutsch/pdf (accessed April 15, 2010). 